\title{
Exploration of basic software talents training in application-oriented college under the mode of cooperative education
}

\author{
Ruchan Dong \\ School of Software engineering \\ Jinling Institute of Technology \\ NanJing, China Country \\ ruchandong@jit.edu.cn \\ Haijing Li \\ Nanjing software institute \\ Jinling Institute of Technology \\ NanJing, China Country \\ lihaijing@jit.edu.cn
}

\author{
Qi Shen \\ Nanjing software institute \\ Jinling Institute of Technology \\ NanJing, China Country \\ shenqi@jit.edu.cn \\ Weiyan Shen \\ Nanjing software institute \\ Jinling Institute of Technology \\ NanJing, China Country \\ shenweiyan@jit.edu.cn
}

\begin{abstract}
The basic software, as the core of high-end software industry, is the foundation for the development of software and information security industry, and also a decisive factor to the development of national software and information technology. Currently, our training on professional basic software talents is weak in college and the training system is imperfect, to make up for which, the mode of basic software talents training in application-oriented college under cooperative education is proposed in the essay, which will have an influence on the training mode of basic software talents.
\end{abstract}

Keywords-Basic software; application-oriented college cooperative education; Institute of Software of Chinese Academy of Sciences (ISCAS)

\section{INTRODUCTION}

The area of basic software starts late in our country with a large part of markets occupied by foreign products for a long term, leaving domestic basic software manufacturers struggling at the edge. The exposure of "Prism-gate Scandal" indicates that our information system and network system nearly have no ability to defense facing foreign information monitoring program if basic software like operating system is under the control of foreign countries, then China has no chance to be an information power. Therefore, it is critical that we should develop basic software industry with great efforts.

The cooperative education pushes forward the transformation of traditional teaching mode, realizing sharing of resources and complementary advantages among corporation, college and research institute. Talent training under the mode of cooperative education aims at enhancing students' overall quality, innovative spirit and application

\section{Foundation item:}

(1)Research and practice on basic software talent training based on industryuniversity-research cooperation education mode 2015JYJG08.

(2) Research on innovative basic software talents industry-university-research cooperative training mode (2015JSJG161).

(3)Exploration of autonomic learning and innovation ability training in applicative talent majoring in computer under the mode of MOOC mixed teaching system 40714011. ability, which carries out knowledge-based classroom education mainly and scientific research with production practice, which depends on direct experience and creative ability, as effective complement. This kind of training, combining knowledge and practice, is an essential way to cultivate high-level innovative talents, which is also efficient.

\section{JINLING INSTITUTE OF TECHNOLOGY TRAIN BASIC SOFTWARE TALENTS UNDER THE SUPPORT OF INSTITUTE OF SOFTWARE OF CHINESE ACADEMY OF SCIENCES}

Institute of Software of Chinese Academy of Sciences (ISCAS), the national engineering research center of basic software, has the senior technical strength and rich practical experience over the development of core technology and research on cutting-edge technology in the area of basic software.

Jinling Institute of Technology(JIT), a provincial and application-oriented college, implemented four development strategies "Nanjing strategy, technology strategy, resource strategy and quality strategy" vigorously in recent years, trying to construct an application-oriented university with software dominating and other disciplines developing in coordination.

A project to train excellent software engineers was launched by ISCAS and JIT to improve the level of basic software education and promote the undergraduate cultivation of basic software talents, giving impetus to the transformation and upgrading of the Nanjing University of Software Technology. The project built the mechanism of integral coordination among government, industry, academia, research and application by reforming the talent training mode. In the process, ISCAS and JIT opened to each other, sharing 
resources and complementary advantages in education resources, research facilities, technology platforms and other aspects.

The project of training excellent software engineers adopted teaching method of integrating theory with practice and its faculties mainly come from ISCAS, aiming at cultivating application-oriented basic software talents.

\section{ThE ORIENTATION OF BASIC SOFTWARE TALENTS TRAINING IN APPLICATION-ORIENTED COLLEGE AMONG CORPORATION, \\ COLLEGE AND RESEARCH INSTITUTE}

At present, many provincial colleges emphasize "Ying Yong" (application), then the two basic supporting points are "Ying", stressing "why to learn", and "Yong", stressing "what to learn". Specifically, "why" and "what" are the two questions we need to answer.

"Why" means to "why to learn". In current situation of international information industry, if a country has no independent basic software, its information security will not be guaranteed. Nanjing has implemented a series of plans developing software as regarding software industry as one of the main means to transform economic pattern of the city. JIT, as a provincial and application-oriented one, its development and orientation should be in compliance with "Nanjing" features. Therefore, the essay proposes the subject on research and practice of basic software talents training under the mode of cooperative education, complying with the strategic needs of state, local and school, according to Fig.1.

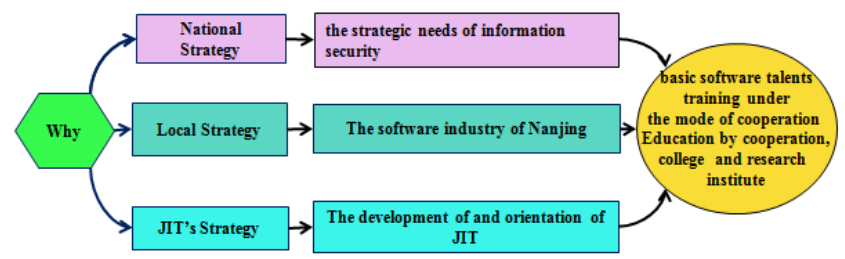

Fig.1. Aim and content of "why"

"What" means to "what to learn". Though the absolute number of software talents is large, the basic software research talents are in need. ISCAS summarized a curriculum system suitable for undergraduate college with operating system as a foothold and basic software skills as the goal, under years of experience on basic software research and practice. As showed in Fig.2, in two latter years of their college lives, the school needs to intensify the study of one integrated course for each term, with two first terms learning "Linux Application Programming Technology" and "Linux Kernel Programming Technology", by which students can master Linux development technique and Linux kernel operating mechanism, and latter two terms learning "Operating System Customization Technology" and "Operating System Depth Design", by which students can grasp the core concept and technique of operating system and design the specific operating system modules successfully. In this way, students will get basic software development skills and their abilities of application and practice will also be strengthened step by step.

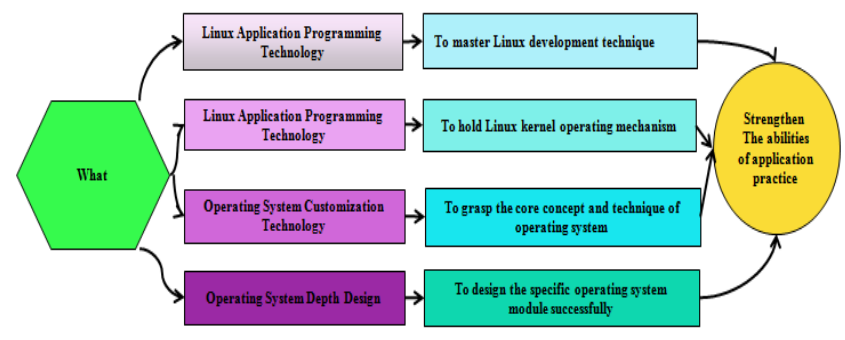

Fig.2. Aim and content of "what"

Jinling Institute of Technology is an undergraduate college experienced in training application-oriented talents, which tried to make changes in talent training system and gained valuable experience. In the cooperation with ISCAS, it explored unique talent training system and teaching mode.

\section{A. " $2+2$ ” ladder-type training system}

The essay proposes talent training system of " $2+2$ " laddertype as showed in Fig 3. The former two years of school life are for professional basic learning, after which students being selected into the project of training excellent software engineers will be trained to promote their basic software development skills in latter two years, in which period four courses will be designed for four terms with learning operating system as a start, as well as comprehensive training, graduation practice and graduation project.

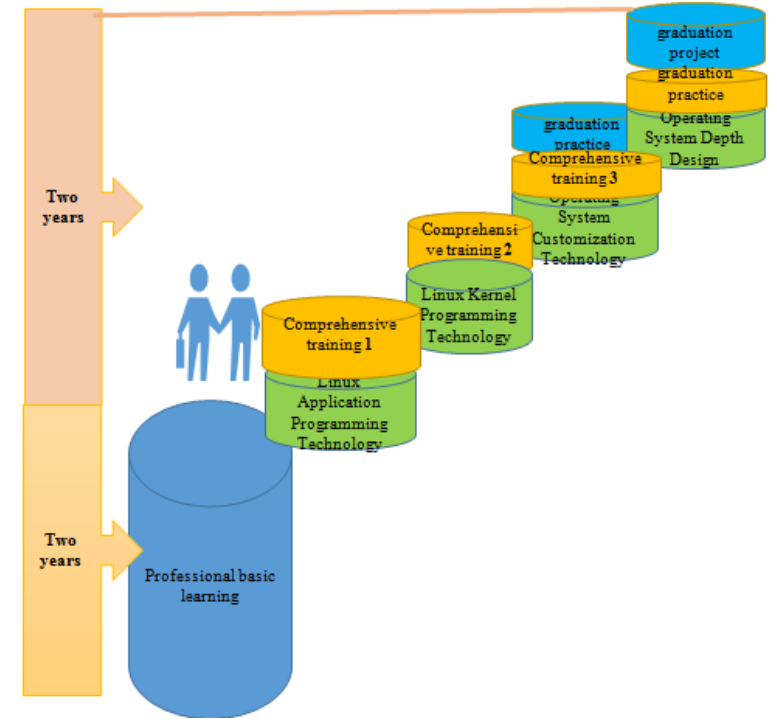

Fig.3. "2+2” ladder-type training system

\section{B. training basic software talents pertinent to the project}

From their third year in college, students will take courses for training basic software talents pertinent to the project, which is to practice and promote their basic software development skills with learning operating system as a start then getting deeper by taking four courses in four terms as follows in sequence, "Linux Application Programming Technology", "Linux Kernel Programming Technology", "Operating System Customization Technology" and 
“Operating System Depth Design". What's more, at the end of each term, there is a comprehensive training for a whole month. ISCAS will provide the comprehensive practice subjects by dividing its own research project into several parts, which are for certain teams. They are supposed to finish the designs within certain time under no direction. In the last year, a part of students will be selected according to their performances to practice and do the graduation project at its base in Shanghai, preparing for employment.

\section{The 1: 2: 7 teaching mode}

In the process, the courses consist of three sections: theoretical teaching, discuss and practice with proportions of about 1:2: 7 in time allocation. Seventy percent of practice emphasizes training application ability and ninety percent of discuss and practice is supposed to improve their abilities of independent learning, innovation, cooperation and expression. Though theoretical teaching only takes ten percent of the whole lesson, it adopts the mode of online and aspectant teachings by watching online video courses with teachers analyzing in real time, which asks for students' ability of independent learning and requires exchanges between teachers and students, solving the questions in time. In order to support the teaching mode of 1: 2: 7 and make full use of internet, we created an online community as a platform for the research of operating system, including learning resources like lecture notes, voice PPT, research guidance, practice guide, instruction video and so on for online learning. In the community, students can also take part in chapter test and final examination, communicate with teachers from ISCAS in real time and participate in technique research contest with award organized by them.

\section{CONCLUSION}

The major content of this research is a guidance to improve the curriculum system of application-oriented software talents training in our school, innovating talent training mode with obvious application characteristic and improving the quality of talent training as well as increasing employment rate. The curriculum system and teaching mode mentioned in the research are also of significance to other majors and even guides to the training of basic software talents nationwide.

\section{REFERENCES}

[1] Guangnan Ni, "Have a view on China's software industry from the perspective of basic software," Software world,vol 9, 2009,pp.7-9.(In chinese)

[2] Guangnan $\mathrm{Ni}$, "Cyberspace security will help the rise of China's software industry," Information security and communication security,vol 12,2014,pp.10-11. (In chinese)

[3] Dan Tian, Yang Zhao, "From the innovation of service to basic software: a research on growth paradigm of technology in Chinese software companies," Soft Science of China, vol 5,2014, pp. 129-140. (In chinese)

[4] JiFeng He , Ningkang Jiang "Collaborative innovation, cultivate highend software talents," university teaching in China, vol 10,2014,pp:9-16. (In chinese)

[5] Kehe Ma, "Analysis on cooperative education and applied talents - a case study of Tongling college,"'The Magezine of Chizhou College vol 10,2014.,pp.109-111. (In chinese)

[6] Chunsheng Yang, Qin Sun, Wei Hao, "A research on the new mode of undergraduate talents participating in innovative project," Education in Colleges and Universities of JiangSu,vol 1,2010,pp:81-83. (In chinese)

[7] Qi Shen, Yan Zhang, "Construct practice teaching system in reference to the concept of CDIO," The magazine of computer Education, vol 10,2010,pp:57-60. (In chinese)

[8] "The White Paper 2014 on the development of the software industry in Nanjing"(In chinese)

[9] Yaping Wu, "Evaluation of the mode of inform course: education and vocation," Education and vocational, vol 10,2010,pp:31-33. (In chinese)

[10] Yurong Qian,Qiong Yu,Weiyuan Wang,Shengwei Tian, "The training mode of master of software engineering under cooperative education," Teacher,vol 17,2014,pp:22-24. (In chinese) 